\title{
DAMPAK BAGI ANAK YANG KECANDUAN GADGET
}

\author{
Galih Tri Winata \\ Program Studi Keperawatan, Universitas Muhammadiyah Bengkulu \\ galihtriwinata@gmail.com
}

\begin{abstract}
ABSTRAK
Gadget saat ini marak diperbincangkan dikonsumsi oleh masyarakat saat ini karna kecanggihan teknologi gadget diciptakan dalam bentuk perangkat kecil yang fleksibel dan nyaman dibawa kemana saja. Bukan hanya orang dewasa, saat ini anak-anak mampu menggunakan gadget dalam kehidupan sehari-hari, dan mereka nyaman dalam menggunakan sehingga dapat mengakibatkan terjadinya kecanduan gadget yang dapat berdampak pada perkembangan anak berupa gangguan mental, emosi dan perilaku negatif anak. Jenis penelitian mengunakan metode deskriptif analitik yaitu dengan melihat gambaran kejadian gangguan mental dan emosional pada anak usia 3-6 tahun. Sampel penelitian ini adalah Anak usia 3-6 tahun sebanyak 100 orang dengan menggunakan teknik purposive random sampling yaitu teknik penentuan sampel dengan memenuhi karakteristik tertentu.Simpulan, sebagian besar anak mengalami kecanduan gadget dan sebagian besar anak beresiko mengalami gangguan emosial jika orang tua tidak melakukan tindakan bijak dalam penggunaan gadget.
\end{abstract}

Kata Kunci : Gadget, Gangguan Mental, Kecanduan, Gangguan Emosional 


\title{
IMPACT FOR GADGET ADDICTED CHILDREN
}

\author{
Galih Tri Winata \\ Nursing Study Program, Bengkulu Muhammadiyah University \\ galihtriwinata@gmail.com
}

\begin{abstract}
The current gadget is widely discussed being consumed by the public today because of the sophistication of gadget technology created in the form of a small device that is flexible and convenient to carry anywhere. Not only adults, nowadays children are able to use gadgets in their daily lives, and they are comfortable using them, which can lead to gadget addictions that can have an impact on children's development in the form of mental disorders, emotions and negative behavior of children. This type of research uses descriptive analytic method that is by looking at the picture of the incidence of mental and emotional disorders in children aged 3-6 years. The sample of this research is children aged 3-6 years as many as 100 people using purposive random sampling technique, which is the technique of determining the sample by meeting certain characteristics. Conclusion, most children are addicted to gadgets and most children are at risk of experiencing social problems if parents do not act wisely in the use of gadgets.
\end{abstract}

Keywords: Gadgets, Mental Disorders, Addiction, Emotional Disorders 


\section{PENDAHULUAN}

Gadget saat ini marak diperbincangkan dikonsumsi oleh masyarakat saat ini karna kecanggihan teknologi gadget diciptakan dalam bentuk perangkat kecil yang fleksibel dan nyaman dibawa kemana saja. Bukan hanya orang dewasa, saat ini anakanak mampu menggunakan gadget dalam kehidupan sehari-hari, dan mereka nyaman dalam menggunakan sehingga dapat mengakibatkan terjadinya kecanduan gadget yang dapat berdampak pada perkembangan anak berupa gangguan mental, emosi dan perilaku negatif anak.

Sebuah survei penelitian yang dilakukan melalui polling melalui saluran televisi Channel News didapatkan bahwa hasil survei menunjukkan sebanyak 47 persen dari orang tua mengungkapkan bahwa anak mereka banyak menghabiskan waktu seharian di depan layar gadget ada yang membuka youtube, game, bahkan ada yang menggunakan sebagai sarana belajar seperti coloring, dll. Sedangkan sebanyak 43 persen lainnya mengaku bahwa anak mereka telah memiliki ikatan emosi dengan perangkat mobile yang dimiliki seperti menangis, marah jika gadget mereka diambil. Rata-rata anak, dari survei itu, menghabiskan waktu rata-rata lebih dari tiga jam untuk berkutat di depan layar gadget dalam sehari. Biasanya mereka bermain games, melihat video atau Youtube, dan berinteraksi di sosial media, hasil penelitian yang dilakukan Profesor Sonia Livingstone dari London School of Economic (Ramadhan, Agung, 2017; Depkes RI, 2013).

Beberapa kasus yang tengah marak akhirakhir ini terkait gangguan kejiwaan (mental, emosional dan perilaku) yang dialami anak akibat kecanduan gadget pada anak merupakan masalah ini dianggap penting dan harus di waspadai oleh seluruh orangtua yang memiliki anak terutama usia presekolah dengan kebiasaan memainkan gadget. Untuk menghindari hal tersebut perlu dilakukan deteksi dini dalam penilaian status mental dan emosional anak sejak dini pada usia 3-6 tahun (IDAI, 2013).

Saat ini belum terlalu banyak penelitian yang mengacu pada gangguan mental dan emosional secara lebih luas terutama pada anak di Indonesia yang merupakan dampak dari kecanduan gedget yang merupakan hasil negatif dari perkembagan teknologi yang sedang berkembang saat ini. Meskipun ada beberapa faktor risiko lain yang menjadi penyebab terjadinya gangguan emosional pada anak misalnya jenis kelamin anak, jumlah saudara dalam keluarga, trauma emosional pada anak, kegagalan dalam bersosialisasi di masyarakat akibat isolasi yang dilakukan dan pola asuh yang tidak baik serta riwayat komplikasi saat kelahiran anak dan masa awal bayinya, riwayat penyakitkronis, 
ketidakharmonisan dalam keluarga, faktor keturunan akibat orang tua menderita sakit mental atau ketergantungan obat, dan pola asuh orang tua. dan lain-lain, beberapa faktor diatas merupakan salah satu faktor pencetus gangguan mental dan emosional akan bermunculan lebih dini (Bayer, 2011). Fenomena yang terjadi ini dapat menjadi fenomena gunung es serta menjadi beban dan masalah baru kesehatan bagi pemerintah, dan menjadi penyebab rusaknya generasi penerus bangsa (CDC, 2013).

\section{METODE}

Jenis penelitian mengunakan metode deskriptif analitik yaitu dengan melihat gambaran kejadian gangguan mental dan emosional pada anak usia 3-6 tahun.Sampel penelitian ini adalah Anak usia 3-6 tahun sebanyak 100 orang dengan menggunakan teknik purposive random sampling yaitu teknik penentuan sampel dengan memenuhi karakteristik tertentu.

\section{HASIL}

Hasil penelitian ini menunjukkan bahwa sebagian besar responden dengan tingkat kecanduan tinggi. Saat dilakukan wawancara kepada orang tua mengungkapkan bahwa diawali dengan meminjamkan sampai membelikan gadget yang canggih dengan model yang sesuai dengan keinginan anak, demi memberika kebahagiaan pada anak, mengikuti trend.Selain itu orangtua yang memiliki karir diluar rumah gadget sengaja difasilitasi untuk digunakan agar akatifitas anak terpantau dan dapat berkomunikasi dengan anak yang ada dirumah, sehingga orang tua mengetahui semua aktifitas yang dilakukan anak.

Sedangkan ibu dengan pekerjaan sebagai ibu rumah tangga membelikan gadget pada anak dengan tujuan mengalihkan perhatian sianak agar tidak menganggu aktifitas ibu dalam mengerjakan pekerjaan rumah tangga. Awalnya tujuan mereka berhasil, untuk komunikasi dan sebagai pengalihan perhatian pada anak. Namun lamakelamaan anak mulai mencoba lebih aktif untuk mencoba fitur serta aplikasi lain yang lebih menarik, dan menantang sesuai dengan keinginan mereka masing-masing. Hal ini akan membuat anak akan lebih terfokus pada gadgetnya dan mulai meninggalkan dunia bermain mereka, dan merasa lebih nyaman dengan beberapa fitur yang ditawarkan di gadget.

\section{PEMBAHASAN}

Ada beberapa perilaku anak yang mengalami kecanduan gadget yang harus diwaspadai oleh guru maupun orang tua yaitu: (1) Ketika keasyikan dengan gadget anak jadi kehilangan minat dalam kegiatan lain. (2) Anak mulai tidak tertarik melakukan interaksi, atau bergaul dengan teman sebaya untuk bermain diluar rumah, (3). Anak mulai menunjukan emosional yang kadang tidak bisa dikontrol, bahkan 
tantrum ketika orang tua mengambil, merenut, atau melarang anak saat sedang asyik menggunakan gadget. (4) anak mulai menunjukan perilaku negatif, dengan berani berbohong atau mencuri-curi waktu untuk bermain gadget saat orang tua sedang asyik beraktifitas, atau saat sedang tidur. Beberapa perilaku diatas merupakan sebagian tanda dan gejala pada anak bahwa mereka sedang membutuhkan bantuan dalam menghentikan aktifitasnya dengan kecanduan bermain gadget. Meskipun sebenarnya bermain gadget memiliki beberapa manfaat untuk membentuk sikap cekatan, melatih fokus, serta meningkatkan kecakapan dalam berbahasa inggris (Erol Dkk, 2005).

Dampak negatif pada anak yang menggunakan gadget dapat membuat anak mengalami ketagihan, sampai dengan fase kecanduan gadget. Anak akan membuang waktu sia-sia dalam bermain, bahkan anak menahan rasa lapar, haus, dan keinginan untuk melakukan toileting. Anak-anak mulai malas melakukan aktiftas rutin seperti belajar, bermain, makan, melakukan aktifitas seperti bermain bola pada anak laki-laki, pada anak perempuan bermain bersama teman sebaya, padahal beberapa aktiftas berpengaruh penting dalam mendukung kematangan dan perkembangan anak di berbagai aspek perkembangan yang ada pada dirinya, dan penunjang dalam perkembangan otak. Jika anak dalam waktu lama terpapar dalam penggunaan gadget, dan menjadikan gadget sebagai aktiftas rutin yang dilakukan sehari-hari maka hal ini menjadi salah satu faktor penyebab terganggunya perkembangan otak.

\section{KESIMPULAN}

Berdasarkan hasil penelitian mengenai deteksi dini deteksi dini gangguan mental dan emosional pada anak yang mengalami kecanduan gadget dapat ditarik kesimpulan sebagai berikut: Bahwa sebagian besar anak mengalami kecanduan gadget dan sebagian besar anak beresiko mengalami gangguan emosial jika orang tua tidak melakukantindakan bijak dalam penggunaan gadget, usia 1-5 tahun merupakan usia keemasan dalam membentuk semua karakter diri, sehingga pendampingan dan pola asuh yang baik dari orang tua sangan dibutuhkan dalam proses tumbuh dan kembang anak dari segala aspek.

\section{REFERENSI}

Dwi Wulandari \& Dilfera Hermiati. (2019). DETEKSI DINI GANGGUAN MENTAL DAN EMOSIONAL PADA ANAK YANG MENGALAMI KECANDUAN GADGET. Jurnal Keperawatan Silampari 3 (1) 382-392 https://doi.org/10.31539/jks.v3i1.843 
